\title{
KONTRIBUSI IMPLEMENTASI MANAJEMEN BERBASIS NILAI-NILAI KEARIFAN LOKAL TRI HITA KARANA, KEPEMIMPINAN PELAYAN KEPALA SEKOLAH, KECERDASAN SPIRITUAL, DAN KEPUASAN KERJA TERHADAP KOMITMEN ORGANISASIONAL GURU DI SMP NEGERI DI KECAMATAN SAWAN KABUPATEN BULELENG PROVINSI BALI
}

\author{
Putu Yulia Angga Dewi ${ }^{1}$, Anak Agung Gede Agung ${ }^{2}$, Kadek Rihendra Dantes ${ }^{3}$
}

\author{
Program Studi Administrasi Pendidikan \\ Universitas Pendidikan Ganesha \\ Singaraja, Indonesia
}

\begin{abstract}
e-mail : \{yuliaanggadewi@yahoo.co.id, agung2056@undiksha.ac.id, rihendra79@gmail.com\}
\end{abstract}

\begin{abstract}
Abstrak
Penelitian ini bertujuan untuk mengetahui besaran kontribusi antara variabel manajemen sekolah berbasis nilai-nilai kearifan lokal Tri Hita Karana, kepemimpinan pelayanan kepala sekolah, kecerdasan spiritual, kepuasan kerja dengan variabel komitmen organisasional guru. Penelitian ini tergolong jenis ex-post facto dengan rancangan analisis jalur (path analisis). Populasi dalam penelitian ini sejumlah 163 orang. Sampel penelitian diambil secara acak yang berjumlah 132 orang. Pengumpulan data menggunakan kuesioner dari variabel manajemen sekolah berbasis nilai-nilai kearifan lokal tri hita karana, kepemimpinan pelayanan kepala sekolah, kecerdasan spiritual, kepuasan kerja dan komitmen organisasional guru. Hasil penelitian menunjukkan bahwa seluruh hipotesis signifikan dan memiliki kontribusi terhadap komitmen organisasional. Sesuai dengan hasil analisis menunjukkan bahwa manajemen sekolah berbasis nilainilai kearifan lokal Tri Hita Karana, kepemimpinan pelayanan kepala sekolah, kecerdasan spiritual, dan kepuasan kerja secara simultan (bersama-sama) memberi kontribusi yang signifikan terhadap komitmen organisasional di SMP Negeri Kecamatan Sawan sebesar 0,914 atau 91,4\%. Berdasarkan hasil analisis model regresi $\hat{y}=75,915$ $+0,741 X_{1}+0,826 X_{2}+0,716 X_{3}+0,732 X_{4}$ dengan Freg $=224,104(p<0,05)$.
\end{abstract}

Kata kunci: Manajemen Sekolah Berbasis Nilai-nilai Kearifan Lokal Tri Hita Karana, Kepemimpinan Pelayanan Kepala Sekolah, Kecerdasan Spiritual, Kepuasan Kerja dan Komitmen Organisasional Guru.

\footnotetext{
Abstract

This study aims to determine the amount of contribution between school management variables based on local wisdom values Tri Hita Karana, leadership leadership, spiritual intelligence, job satisfaction with organizational commitment variable of teachers. This research belongs to ex-post facto type with path analysis design (path analysis). The population in this study amounted to 163 people. The study sample was taken randomly which amounted to 132 people. Data collection used questionnaires from school management variables based on local wisdom values of tri hita karana, headmaster service leadership, spiritual intelligence, job satisfaction and organizational commitment of teachers. The results show that all hypotheses are significant and contribute to organizational commitment. In accordance with the results of the analysis indicates that
} 
school management based on local wisdom values Tri Hita Karana, head service leadership, spiritual intelligence, and job satisfaction simultaneously contributed significantly to organizational commitment in SMP Negeri Kecamatan Sawan by 0.914 or $91.4 \%$. Based on the result of regression model analysis $\hat{y}=75,915+0,741 \mathrm{X} 1+$ $0,826 \times 2+0,716 \times 3+0,732 \times 4$ with Freg $=224,104(p<0,05)$.

Keywords: School Based Management of Local Wisdom Values Tri Hita Karana, Headmaster Service Leadership, Spiritual Intelligence, Job Satisfaction and Master's Organizational Commitment

\section{PENDAHULUAN}

Pendidikan adalah tonggak kemajuan bangsa, menjadi bangsa yang maju tentu merupakan cita-cita yang ingin dicapai oleh setiap negara di dunia. Sudah menjadi suatu rahasia umum bahwa maju tidaknya suatu negara dipengaruhi oleh faktor pendidikan. Pendidikan merupakan proses mencetak generasi penerus bangsa yang berkualitas. Oleh karena itu, mencerdaskan kehidupan bangsa dijadikan salah satu tujuan nasional yang wajib diperjuangkan olah seluruh pihak. Dari tujuan nasional tersebut, jelas terlihat bahwa Indonesia menaruh harapan besar terhadap pendidikan karena pendidikan akan membentuk keseluruhan aspek pada diri seseorang sehingga menjadi manusia yang unggul dan berkualitas.

Loyalitas yang tinggi terhadap organisasi akan terlihat pada guru yang memiliki komitmen yang tinggi. Komitmen organisasional pada guru yang memiliki komitmen yang tinggi biasanya akan meningkatkan kinerja dan sebaliknya jika guru memiliki tingkat komitmen rendah maka kinerjanya juga akan rendah.

Jika manajemen sekolah disandingkan dengan nilai-nilai kearifan lokal Tri Hita Karana sebagai nilai dasar proses pelaksanaan kegiatan. Pendidikan Tri Hita Karana adalah pendidikan yang bertujuan menghasilkan luaran berkarakter dan berbudaya Tri Hita Karana. Pendidikan diharapkan memiliki karakter moralitas dan kebudayaan yang didasari oleh nilai-nilai ideologi Tri Hita Karana. Budaya preservatif dan budaya progresif tumbuh dengan ciri-ciri adanya kreativitas, inovasi, dan produktivitas yang tinggi ditengah-tengah dunia pendidikan (Sudira, 2014).

Tradisi Tri Hita Karana menekankan perlunya menyeimbangkan kinerja budaya dan kinerja individu dalam setiap kegiatan pendidikan. Melestarikan kearifan lokal (Tri Hita Karana) harus dibarengi dengan pelestarian komitmen organisasional guru. Manajemen sekolah berbasis nilai-nilai kearifan lokal Tri Hita Karana berpengaruh signifikan terhadap kepuasan kerja guru serta komitmen organisasional. Nilai-nilai yang terkandung dalam Tri Hita Karana sangat penting untuk diterapkan dalam manajemen sekolah agar dapat meningkatkan kecerdasan spiritual, kepuasan kerja guru. Namun tidak dapat dipungkiri faktor kepemimpinan pelayanan kepala sekolah sangat berperan penting dalam keberhasilan implementasi manajemen sekolah berbasis nilai-nilai kearifan lokal Tri Hita Karana.

Komitmen ditunjukkan dalam sikap penerimaan, keyakinan yang kuat terhadap nilai-nilai dan tujuan sebuah organisasi, begitu juga adanya dorongan yang kuat untuk mempertahankan keanggotaan dalam organisasi demi tercapainya tujuan organisasi atau dengan kata lain komitmen organisasional merupakan loyalitas seorang guru pada suatu pekerjaan atau organisasinya.

Kecerdasan spiritual (spiritual quotient) adalah kemampuan seseorang untuk memaknai kehidupannya dalam kehidupan ini. Kecerdasan untuk dapat melakukan segala sesuatu tindakan yang semuannya di awali dan dilandasi oleh pengetahuan dan pemahaman sebagai dasarnya. Kepuasan kerja guru tidak semata-mata hanya mengenai tingginya upah. Karena di berbagai negara maju, ketika upah guru sudah lebih memadai, tetap saja terdapat sejumlah besar guru yang tidak puas bahkan kemudian 
beralih profesi. Ini berarti terdapat banyak faktor yang menunjang terciptanya kepuasan kerja guru di sekolah.

Guna mengantisipasi hal tersebut, telah banyak dilakukan berbagi upaya pembaharuan komitmen organisasional guru di Indonesia, antara lain melalui perbaikan sarana, kurikulum, sistem pengajaran, dan lain sebagainya. Namun demikian, berbagai upaya tersebut belumlah memberikan prioritas kepada unsur guru sebagai pelaksana, terutama dari segi kesejahteraannya. Karenanya, menurut Surya (2003: 5) dalam kenyataannya guru tetap terabaikan dalam perwujudan keberdayaannya sebagai insan pendidikan yang memegang peran penting dalam kemajuan pendidikan bangsa.

\section{METODE PENELITIAN}

Penelitian ini dilaksanakan di SMP Negeri di Kecamatan Sawan, adapun sekolah yaitu: SMP Negeri 1 Sawan, SMP Negeri 2 Sawan, SMP Negeri 3 Sawan dan SMP Negeri 1 Satap. Desain atau rancangan penelitian ini tergolong penelitian deskriptif dan korelasional. Dikatakan deskriptif, karena peneliti berusaha memperoleh informasi yang berkenaan dengan fenomena yang diamati saat ini selanjutnya mendeskripsikan data tentang objek atau variabel yang diteliti (Suharsimi, 1989).

Populasi dalam penelitian ini adalah seluruh guru pada sekolah Menengah Pertama Negeri di Kecamatan Sawan tahun 2017 yang berjumlah sekitar 163 orang guru. Menurut formula Kreje dan Morgan tersebut, jumlah sampel untuk populasi 163 adalah 113. Artinya, bahwa dalam penelitian ini sekurang-kurangnya harus dijaring 113 responden yang dapat dianalisa datanya. Jika dalam penyebaran instrument atau kuisioner pengumpulan data ini hanya disebarkan 113 kuesioner, maka ada kemungkinan tidak seluruhnya dikembalikan

Dengan menggunakan formula Warwich dan Lininger tersebut, akan dapat diantisipasi dan diatasi terjadinya kemungkinan beberapa responden yang tidak mengembalikan atau tidak mengisi kuesioner secara lengkap dan benar, sehingga target jumlah sampel minimal sebesar 132 akan tetap terpenuhi.

Berdasarkan hasil perhitungan diatas, diperoleh jumlah sampel sebanyak 132 orang $80,9 \%$ persen. Dengan cara tersebut, maka berapapun kuesioner yang dikembalikan responden akan dianalisis setelah dikurangi data atau kuesioner yang rusak (tidak lengkap).

\section{HASIL DAN PEMBAHASAN}

Sesuai dengan paparan hasil penelitian, diketahui bahwa terdapat kontribusi implementasi manajemen sekolah berbasis nilai-nilai kearifan lokal Tri Hita Karana, kepemimpinan pelayanan kepala sekolah, kecerdasan spiritual, dan kepuasan kerja terhadap komitmen organisasional guru di SMP Negeri Kecamatan Sawan. Berdasarkan hasil analisis yang telah dilakukan, dapat dijelaskan sebagai berikut. (1) terdapat kontribusi manajemen sekolah berbasis nilai-nilai kearifan lokal Tri Hita Karana terhadap komitmen organisasional sebesar 0,809 atau 80,9\%. Berdasarkan hasil analisis diperoleh $r_{\text {hitung }}=0,806$. Ini berarti $r_{\text {hitung }}=0,806$ signifikan pada $\alpha=0,05\left(r_{\text {tabel }}=0,167\right)$, (2) Terdapat kontribusi kepemimi-pinan pelayanan kepala sekolah terhadap komitmen organisasional sebesar 0,695 atau 69,5\%. Berdasarkan hasil analisis diperoleh rhitung $=$ 0,583 . Ini berarti ${ }_{\text {rhitung }}=0,746$ signifikan pada $\alpha=0,05($ rtabel $=0,167)$. Hal ini berarti bahwa kenyamanan akan kepemimpinan pelayan kepala sekolah menjadi faktor penting untuk meningkatkan komitmen organisasional guru, (3) terdapat kontribusi manajemen sekolah berbasis nilai-nilai kearifan lokal Tri Hita Karana terhadap kecerdasan spiritual sebesar 0,736 atau $73,6 \%$. Berdasarkan hasil analisis diperoleh $r_{\text {hitung }}=0,789$. Ini berarti $r_{\text {hitung }}=0,789$ signifikan pada $\alpha=0,05$ ( $\left.r_{\text {tabel }}=0,167\right)$. Hal ini berarti Spiritual Quotient (SQ) juga mempunyai kekuatan untuk meruntuhkan motivasi lama dan membawa kita ke motivasi yang lebih tinggi, (4) terdapat kontribusi kepemimipinan pelayanan kepala sekolah terhadap kepuasan kerja sebesar 0,853 atau $85,3 \%$. Berdasarkan hasil analisis 
diperoleh $r_{\text {hitung }}=0,876$. Ini berarti $r_{\text {hitung }}=0,876$ signifikan pada $\alpha=0,05\left(r_{\text {tabel }}=0,167\right)$. Hal ini berarti kepala sekolah harus tahu betul dan memahami kebutuhan-kebutuhan para guru ebagai bawahannya di tingkatan manakah mereka berada. Sehingga pemimpin dapat dengan mudah dan tepat memberi kepuasan kepada guru agar kerjanya baik sehingga dapat merasakan akan kepemimpinannya dan dapat meningkatkan prestasi kerjanya, (5) terdapat kontribusi manajemen sekolah berbasis nilai-nilai kearifan lokal Tri Hita Karana terhadap kepemimipinan pelayanan kepala sekolah sebesar 0,873 atau $87,3 \%$. Berdasarkan hasil analisis diperoleh rhitung $=0,830$. Ini berarti rhitung $=$ 0,830 signifikan pada $\alpha=0,05$ ( $\left.r_{\text {tabel }}=0,167\right)$. Hal ini berarti kepemimpinan pelayan mendo-rong adanya penghargaan dan pengembangan individu, pengembangan komunitas, praktik-praktik autentisitas (authenticiry), kepemimpina yang lebih mengutamakan pengikutnya, serta pendistribusian kekuasaan dan status untuk kebaikan semua orang, keseluruhan organisasi, serta pihak-pihak lain yang dilayani oleh organisasi, (6) terdapat kontribusi kepemimipinan pelayanan kepala sekolah terhadap kecerdasan spiritual sebesar 0,858 atau $85,8 \%$. Berdasarkan hasil analisis diperoleh $r_{\text {hitung }}=0,811$. Ini berarti $r_{\text {hitung }}=0,811$ signifikan pada $\alpha=0,05\left(r_{\text {tabel }}=0,167\right)$. Hal ini berarti kepala sekolah harus mampu menghargai orang lain, mengembangkan guruguru, membangun hubungan yang baik dalam suatu organisasi, memperlihatkan autentisitas melalui integritas dan adanya rasa kepercayaan sesama anggota organisasi, serta memiliki visi dam misi yang sama untuk kepentingan tercapainya tujuan organisasi, (7) Terdapat kontribusi manajemen sekolah berbasis nilai-nilai kearifan lokal Tri Hita Karana terhadap kepuasan kerja sebesar 0,841 atau 84,1\%. Berdasarkan hasil analisis diperoleh $r_{\text {hitung }}=0,875$. Ini berarti rhitung $=0,875$ signifikan pada $\alpha=0,05$ $\left(r_{\text {tabel }}=0,167\right)$. Hal ini berarti akan terus mendorong guru untuk melaksanakan tugasnya dengan baik-sebaiknya dalm rangka mencapai tujuan sekolah yang telah ditetapkan, (8) terdapat kontribusi kecerdasan spiritual terhadap komitmen organisasional sebesar 0,80 atau $80,00 \%$. Berdasarkan hasil analisis diperoleh $\mathrm{r}_{\text {hitung }}=0,817$. Ini berarti rhitung $=0,817$ signifikan pada $\alpha=0,05\left(r_{\text {tabel }}=0,167\right)$. Hal ini berarti ketika seorang guru telah memiliki dimensi-dimensi kecerdasan spiritual salah satunya adalah kemampuan untuk bekerja mandiri dan kemampuan untuk meningkatkan kualitas hidup oleh visi dan nilai-nilai, (9) terdapat kontribusi kecerdasan spiritual terhadap komitmen organisasional sebesar 0,815 atau $81,5 \%$. Berdasarkan hasil analisis diperoleh rhitung $=0,822$. Ini berarti $r_{\text {hitung }}=0,822$ signifikan pada $\alpha=0,05\left(r_{\text {tabel }}=0,167\right)$. Hal ini berarti dengan meningkatnya kecerdasan spiritual guru dapat meningkatkan komitmen guru terhadap sekolah, kepekaan guru terhadap siswa, kepedulian guru terhadap lingkungan sekolah serta meningkatkan pengetahuan dan keterampilan guru dalam melaksanakan kewajiban dan tugasnya, (10) terdapat kontribusi manajemen sekolah berbasis nilai-nilai kearifan lokal Tri Hita Karana terhadap komitmen organisasional melalui kecerdasan spiritual sebesar 0,816 atau $81,6 \%$. Berdasarkan hasil analisis diketahui pengaruh langsung antara $X_{1}$ terhadap $Y$ sebesar 0,327 . Sedangkan pengaruh tidak langsung $X_{1}$ melalui $X_{3}$ terhadap $Y$ adalah perkalian antara nilai beta $X 1$ terhadap $X_{4}$ dengan nilai $X_{4}$ terhadap $Y$ yaitu: $0,113 \times 0,327=0,036$. Hal ini berarti Keadaan ini akan terus mendorong guru untuk melaksanakan tugasnya dengan sebaik-baiknya dalam rangka mencapai tujuan sekolah yang telah ditetapkan, (11) terdapat kontribusi manajemen sekolah berbasis nilai-nilai kearifan lokal Tri Hita Karana terhadap komitmen organisasional melalui kecerdasan spiritual sebesar 0,825 atau $82,5 \%$. Berdasarkan hasil analisis diketahui pengaruh langsung antara $X_{2}$ terhadap $Y$ sebesar 0,263 . Sedangkan pengaruh tidak langsung $X_{2}$ melalui $X_{4}$ terhadap $Y$ adalah perkalian antara nilai beta $X 2$ terhadap $X_{4}$ dengan nilai $X_{4}$ terhadap $Y$ yaitu: $0,423 \times 0,263=0,111$. Maka pengaruh langsung yang diberikan $X_{2}$ terhadap $Y$ adalah pengaruh langsung ditambah dengan pengaruh tidak langsung yaitu: $0,263+0,111=0,374$. Hal ini berarti semakin efektif kepemimpinan kepala sekolah melalui kepuasan kerja guru maka semakin tinggi 
pula komitmen guru terhadap organisasinya, namun sebaliknya jika semakin rendah atau berkurang kepemimpinan kepala sekolah melalui kepuasan kerja guru maka semakin rendah pula komitmen guru terhadap organisasinya yaitu sekolah, (12) terdapat kontribusi yang signifikan secara simultan antara manajemen sekolah berbasis nilai-nilai kearifan lokal Tri Hita Karana, kepemimpinan pelayanan kepala sekolah, kecerdasan spiritual, dan kepuasan kerja terhadap komitmen organisasional guru sebesar $91,4 \%$. $\%$. Berdasarkan hasil analisis model regresi $\hat{y}=75,915+0,741 X_{1}+0,826 X_{2}+0,716$ $X_{3}+0,732 X_{4}$ dengan Freg $=224,104(p<0,05)$. Sumbangan terbesar dari faktor kepuasan kerja guru.

\section{PENUTUP}

Bedasarkan temuan penelitian ini, dapat diajukan saran-saran sebagai berikut. (1) kepada kepala sekolah disarankan agar memberikan kesempatan kepada semua guru untuk ikut serta merancang dan melaksanakan program sekolah sesuai dengan manajemen sekolah. Kepala sekolah diharapkan dapat memahami dan mendengarkan saran serta masukan yang diberikan oleh para guru sehingga guru memiliki tingkatn komitmen yang tinggi terhadap ortganisasinya. Menerapkan manajemen berbasis nilainilai kearifan lokal Tri Hita Karana agar lebih operasional sehingga mudah diimplementasikan dalam kehidupan keseharain disekolah, (2) kepada guru disarankan agar dengan kesadaran tinggi aktif mengikuti segala program sekolah dalam rangka meningkatkan kemampuan mengajar sesuai dengan tuntutan kurikulum yang sangat dinamis sehingga dapat lebih memahami persepsi positif terhadap profesinya, memiliki kesadaran penuh untuk peduli terhadap Tuhan, siswa, rekan kerja, dan lingkungan. Selalu bersemangat dalam melaksanakan tugas sehingga dapat meningkatkan komitmen terhadap organisasi. Selalu menjalin hubungan yang baik agar tercipta suasana hati dan lingkungan yang nyaman, (3) kepada peneliti lain disarankan untuk mengembangkan penelitian ini lebih lanjut terutama yang terkait dengan permasalahan dan variabel yang digunakan dalam penelitian ini dengan menggunakan rancangan penelitian dan analisis data yang lebih kaya dan kompleks dengan mengaitkan variabelvariabel yang lain, yang berkaitan dengan komitmen organisasional guru

\section{DAFTAR RUJUKAN}

Agung, A. A. G. 2004. Evaluasi Pendidikan Suatu Pengantar. Singaraja: IKIP Negeri Singaraja Singaraja.

Agung, A. A. G. 2014. Buku Ajar Metodologi Penelitian Pendidikan. Yogyakarta: Aditya Media Publishing.

Agung, A. A. G. 2015. Buku Ajar Evaluasi Pendidikan. Singaraja: Jurusan Teknologi Pendidikan, Fakultas IImu Pendidikan Universitas Pendidikan Ganesha.

Adnyana Retig, Nyoman. 2005, Budaya Tri Hita Karana dan Efektivitas Kepemimpinan, Jurusan Ekonomi pada Fakultas IImu Sosial Universitas Negeri Surabaya, Surabaya.

Anastasi, A. 1982. Psychological Testing. (4th ed.). London: Collier MacMillan Publishers.

Anderson, J. C. dan Gerbing, D. W. 1991. Structural Equation Modelling in Practice: A Review and Recommended Two-Step Approach. Psychological Bulletin, 193(3), pp. 411- 423. 
Ardhana, W. 1987. Bacaan Pilihan dalam Metode Penelitian Pendidikan. Jakarta: Proyek Pengembangan Lembaga Pendidikan Tenaga Kependidikan Direktorat Jenderal Pendidikan Tinggi Departemen Pendidikan dan Kebudayaan.

Ary, D., Jacobs, L.C., dan Razavich, A. 1985. Introduction to Research in Education. 3rd Ed. New York: Holt, Rinehart and Winston.

Best, J.W. 1982. Metodologi Penelilian Pendidikan. Terjemahan Sanafiah Faisal dan Mulyadi Guntur Waseso. Surabaya: Usaha Nasional.

Borg, W.R. dan Gall, M.D. 1983. Educational Research: An Introduction. 4th Ed. New York: Longman.

Daryanto. 2006. Administrasi Pendidikan. Jakarta: Rineka Cipta.

Engkoswara dan Aan Komariah. 2010. Administrasi Pendidikan. Bandung: Alfabeta.

Fraenkel, J. R., \& Norman E.W. 1993. How to Design and Evaluate Research in Educalion. New York: McGraw-Hill Inc.

Sudira, P. 2014. Konsep dan Praksis Pendidikan Hindu Berbasis Tri Hita Karana. Makalah Disajikan dalam Makalah Seminar Eksistensi Pendidikan Hindu dalam Sisdiknas di Era Global. Universitas negeri Yogyakarta, Yogyakarta 8 Mei 2014

Suharsimi Arikunto, S. 1989. Prosedur Penelitian: Suatu Pendekatan Praktik. Jakarta: Bina Aksara 